\title{
Diálogo y comunicación intercultural. Pretextos para reflexionar sobre la relación sujeto-sujeto en la comunicación humana
}

\section{Dialogue and Intercultural Communication. Excuses to Think on Subject-Subject Relationship in Human Communication}

\author{
Vivian Romeu Aldaya \\ Universidad Autónoma de la Ciudad de México \\ mynameisarielversion2@yahoo.com.mx
}

\begin{abstract}
Resumen
El objetivo de este trabajo es intentar recentrar el propósito de la comunicación humana en la relación originaria sujeto-sujeto, relación que está relegada mayormente de los actuales estudios de la comunicación. La relación sujeto-sujeto ocupa un espacio central en el nivel interpersonal de las relaciones comunicativas interculturales, aspecto poco estudiado también por esta esfera de la comunicación. Mediante la reflexión en torno a la naturaleza de la comunicación intercultural, sus retos teóricos, metodológicos y éticos abordaremos analíticamente el concepto de diálogo y su papel en el re-centramiento de la relación sujeto-sujeto en la comunicación humana.
\end{abstract}

Palabras clave: diálogo, interculturalidad, comunicación intercultural, comunicación humana

\begin{abstract}
The objective of this work is to try to recentrar the intention of the human communication in the original relation subject-subject, relation that is relegated mainly of the present studies of the communication. The relation subject-subject occupies a central space in the interpersonal level of the intercultural comunicativas relations, aspect little studied also by this sphere of the communication. By means of the reflection around the nature of the intercultural communication, its theoretical, methodologic and ethical challenges we will analytically approach the concept of dialogue and its paper in the re-centramiento of the relation subject-subject in the human communication.
\end{abstract}

Key words: dialogue, interculturalidad, intercultural communication, human communication. 
El diálogo es una de las formas, quizá la más alta, de simpatía cósmica

Octavio Paz

\section{A modo de introducción, algunas reflexiones sobre la comunicación intercultural y la comunicación humana}

\subsection{La comunicación humana, la conducta y el concepto de interacción}

Desde mucho tiempo atrás hasta nuestros días, a la comunicación se le atribuye no sólo intención, sino también facultad de convencimiento. Este sino de la persuasión intencional como propósito de la comunicación se le debe en primer lugar a Aristóteles, quien en su Poética definió la comunicación como el intento que hace un orador por persuadir a los demás de que su punto de vista es el correcto. De hecho, a mediados del siglo XVII cuando se aplica la retórica aristotélica a las ciencias del alma como la, por aquellos tiempos, incipiente Psicología, se vislumbra que los fines persuasivos de la comunicación van en dos direcciones: el meramente informativo, que apela a la mente, a lo racional; y el emotivo que apela al alma, a las emociones. Posteriormente, en el siglo XX se suma a la retórica un tercer propósito, el de entretenimiento.

Aunque la teoría actual sobre la conducta humana ha superado esta primera versión sobre el propósito de la comunicación -sobre todo porque se ha dado cuenta que tales funciones (informar-persuadir-entretener) no tienen su origen en la conducta- lo comunicativo continúa inserto de alguna manera en esta idea de propósito persuasivo e intencional. El problema es que, tal y como fue concebido por Aristóteles, el fin persuasivo de la comunicación tiene su origen en el discurso, es decir, se trata de un propósito que está vinculado al lenguaje per se y eso resulta una contradicción intrínseca respecto al origen mismo de la comunicación humana, ya que ésta nace de la conducta, es decir, de las acciones y comportamientos humanos en aras de la adaptación de los individuos al mundo ${ }^{1}$. En consecuencia con lo anterior, el objetivo de este trabajo es reflexionar sobre el papel del diálogo en los procesos comunicativos en tanto procesos inscritos al interior de

\footnotetext{
${ }^{1}$ La idea de adaptación al mundo mediante la comunicación ha sido expuesta ampliamente por Feuerbach (1987), Berlo (1979) y Piaget (1973); el primero en términos de necesidad de socialización, el segundo en términos de dominación, y el tercero a través de lo que llamó adaptación cognoscitiva, aunque en la realidad ninguna de estas acciones se dan de forma aislada, sino más bien relacionadas las unas con las otras. Desde sendas perspectivas, se considera a la comunicación como aquello que hace interdependientes al sujeto y al mundo (lugar donde también se hallan los otros sujetos) y lo que enlaza socialmente a los sujetos de forma necesaria.
} 
las relaciones sociales e interpersonales entre sujetos, y entre sujetos y su entorno, que son a su vez lo que constituye la base y soporte de la construcción de la subjetividad y experiencia vital de individuos y grupos en los marcos de un saber intersubjetivo que sirve de referencia para la acción y el pensamiento individual y colectivo.

Partimos de considerar a la comunicación como una red de relaciones de interdependencia significativa entre los sujetos, y entre éstos y el entorno. Mediante la comunicación los sujetos además de entenderse y relacionarse entre sí, se adaptan a la realidad transformándola, al tiempo que se transforman a sí mismos durante dicha adaptación. Los procesos de adaptación forman parte de los procesos de socialización de individuos y grupos (Berger y Lukhmann, 1998), y estos a su vez sólo pueden tender a la gestación de interdependencias significativas mutuas mediante la comunicación, ya sea verbal o no verbal, y a nivel interpersonal, intergrupal, institucional y/o cultural.

La comunicación humana, así entendida, se concibe como un tipo de interacción simbólica, es decir, significativa, cuyo desarrollo genera afectaciones o modificaciones mutuas entre los hablantes (Bateson y Ruesch, 1984). Dichas transformaciones, sin embargo, no siempre se hacen visibles en las situaciones comunicativas cotidianas, mucho menos en las interacciones sociales, aunque ello no debe hacernos creer que no se dan. Uno de los objetivos de este trabajo es justamente dar cuenta de estos procesos mediante el posicionamiento del concepto de diálogo como expresión teleológica de la comunicación en tanto acción transformadora del sujeto que se despliega a través del lenguaje, mediante la configuración de una lógica de significación e interpretación que pone en relación al sujeto con la otredad.

En ese sentido, el carácter intersubjetivo de la comunicación posibilita la recuperación de la noción prístina de la comunicación como puesta en común, cuya etimología indica su procedencia del prefijo con que significa aportación y del vocablo munis que significa servicio, trabajo. Conmunis, es decir, lo que se aporta como servicio o utilidad (o lo que es aceptado en común) se torna así la base filológica de todo sentido de intercambio y compartimiento en el que se soporta la comunicación, por ello la comunicación nace, conceptualmente hablando, como una relación de servicio y aceptación hacia y del otro, por lo que se instala, en suma, como una relación de comunión.

No obstante lo anterior, esta comunión afín a vocablos como comunidad y colectividad no indica un criterio numérico para definir la comunicación; estos argumentos, de hecho, son muy extendidos cuando se habla de sus tipos o niveles. La idea de comunidad y colectividad, en cambio, más bien se refiere al hecho de que la comunicación es un fenómeno que apunta a lo intersubjetivo, no sólo ni básicamente en un sentido de confluencia -como apuntan algunos enfoques apostólicos y/o terapéuticos sobre lo comunicativo-, sino más bien en términos de intercambio e interdependencia, a consecuencia de la interacción. 
Debido a ello, no debe pensarse que la comunicación es fenómeno o proceso que apunta siempre a la unión o a la coincidencia de la acción comunicativa en términos morales o éticos, mucho menos a su aceptación o asimilación, aspectos estos que adquieren mucha relevancia para algunos teóricos cuando se habla de comunicación intercultural. La comunicación se gesta a lo largo de la historia en el ámbito de lo socialcultural, lo que indica que obedece también e insoslayablemente a una memoria, a una tradición y en ese sentido, se debe en última instancia al poder ${ }^{2}$.

Lo anterior significa que el intercambio de información fruto de un fenómeno comunicativo no puede ser más que un intercambio gestado al calor de una interacción entre sujetos en el marco de lo social-cultural, y por ende en las coordenadas de un suceso que está inscrito en una historia tanto a nivel macro como tiempo histórico concreto, como a nivel micro, es decir, a nivel de la historia personal de cada sujeto, de su experiencia biográfica basada también inevitablemente en la memoria histórica de una cultura, de una comunidad o de un grupo. En resumen: podemos afirmar que el sentido interactivo que otorgamos a la comunicación estriba en la imposibilidad de que ésta pueda darse de forma ajena a la interacción entre sujetos, o entre sujetos y el entorno, ya que la interacción es condición de la comunicación. La interacción ocurre necesariamente en lo social, aunque no por ello debemos dar importancia solamente al marco social y/o institucional que se construye en y a partir de la misma, sino también a lo que ocurre en la complejidad de lo subjetivo.

\footnotetext{
${ }^{2}$ Una de las premisas para el análisis de interacciones comunicativas estriba justamente en su asimetricidad, es decir, en su configuración desigual desde el acto mismo de comunicación: "Quien habla tiene el poder de decir mientras el que escucha no". Claro está, puesto así en blanco y negro, la comunicación se torna un proceso lineal y simple, lo que dista mucho de la realidad. Aquel que tiene el poder de decir -que está dado por el instante mismo en el que dice- se corresponde con la figura del emisor, es decir, con una categoría conceptual que apela al que emite; pasa lo contrario con el receptor, es decir, con quien recibe la información proveniente del emisor. Sin embargo, en la realidad del fenómeno comunicativo, sobre todo si se trata de una conversación cara a cara, es que los roles de emisor y receptor son intercambiables ya que cuando el que emite dice, en ese momento ejerce el poder de decir, cosa que no sucede cuando escucha. Por otra parte, tanto durante un fenómeno comunicativo concreto como durante el proceso social de la comunicación, se observa el intercambio de roles de emisor y receptor entre los hablantes, lo que implica centrar la atención en la relación de interacción propiamente dicha, en la que el despliegue de otros factores como el contexto espacio-temporal, los significados previos con los que cuentan los hablantes, la manera en que se despliega el poder mediante los procesos de legitimación de sentidos que se construyen a partir de la puesta en marcha de las relaciones históricas entre grupos sociales y culturales, la naturaleza directa o indirecta de la interacción, el ambiente, etc., inciden en la configuración de las asimetrías propias de toda comunicación.
} 
1.1.1 El campo académico de la comunicación en torno a la relación sujeto-sujeto en la comunicación humana

Los orígenes del campo de la comunicación están vinculados tanto a la sociología como a la psicología. La definición de los objetos de estudio de la comunicación, de hecho, heredan en lo general las directrices de ambas ciencias, aunque debido a la demanda de investigaciones empíricas sobre opinión pública y el no poco apoyo financiero de los grandes corporativos políticos y mediáticos del momento, los medios y sus efectos en los individuos y grupos se erigen como los objetos de estudio por excelencia de los estudios de comunicación. En pocos años, la investigación en comunicación pasa de los modelos físicos y/o mecánicos y sociológicos que explican el funcionamiento de los medios y su relación con los públicos a los modelos psicológicos, antropológicos y culturalistas, que explican la relación de los sujetos con los medios y con la cultura.

Desde la vertiente sociológica de la comunicación, el estudio de la relación sujetomedios se enfocó en la sociología de corte tradicional, fundamentalmente funcionalista, y la vertiente psicológica de la comunicación alimentó la tendencia conductista propia de la época. Ambas tuvieron ( $y$ tienen) como finalidad comprender dicha relación y en algunas aproximaciones metodológicas contemporáneas se recrea el vínculo entre sujetos, medios y cultura. No obstante, bajo esta perspectiva conceptual, anclada al propósito de persuasión intencional antes mencionado, sigue siendo predominante la relación mediossujetos y no la relación entre sujetos que es la que consideramos constituye el soporte del fenómeno y el proceso comunicativo; y en ese sentido la dirección hacia donde debe tender su propósito.

De lo anterior, resulta que la constitución misma de los estudios de la comunicación se instaura como un conglomerado de investigaciones empíricas que, tomando como objeto de estudio la relación sujetos-medios o, más recientemente, la relación sujetos-cultura (con algún énfasis también en los medios), enfatiza una filiación parcializada y, en nuestra opinión, alejada del fenómeno comunicativo originario, es decir, de la interacción entre sujetos.

El campo de la comunicación, mayormente, ha soslayado las importantes aportaciones conceptuales, metodológicas y empíricas provenientes de la microsociología, la psicología social y la psicología clínica, y con ello ha relegado a un segundo plano los estudios sobre la interacción entre sujetos. Estos antecedentes pueden rastrearse en la Escuela de Chicago ${ }^{3}$,

\footnotetext{
${ }^{3}$ Especialmente los argumentos de Ezra Park a favor de la ecología humana como ciencia de las relaciones entre los seres humanos y su entorno.
} 
en el enfoque metodológico del Interaccionismo Simbólico y en el llamado Colegio Invisible o Escuela de Palo Alto4.

En ese sentido, podemos afirmar que la relación sujeto-sujeto como ámbito de estudio de la comunicación tiene antecedentes tanto en el campo de la sociología como en el de la psicología, aunque lamentablemente no se han desarrollado a profundidad dentro del campo. ${ }^{5}$ Sin embargo, es por una parte el influjo de la globalización, específicamente el aumento de los flujos migratorios internacionales y el sustancial incremento en el flujo de información a nivel internacional y, por la otra, el desarrollo tecnológico en los sistemas de información y comunicación, lo que hace re-centrar la atención de los estudios de comunicación en la relación sujetos-sujetos, sólo que al tratarse de nuevos escenarios mediáticos (NTIC), cuya naturaleza interactiva se diferencia de los escenarios tradicionales de los medios, su estudio y abordaje metodológico pone el énfasis en la interacción mediada entre sujetos. Este nuevo enfoque de un tradicional objeto de estudio, hace al campo de la comunicación voltear la atención de nueva cuenta hacia lo sociológico, pero no sólo a la sociología estructural-funcionalista o crítica, sino también a

\footnotetext{
${ }^{4}$ En los años 50, el sociólogo Erving Goffman, propuso el estudio de las interacciones sociales en pequeñas escalas, es decir, centrándose en las interacciones cara a cara de los individuos en la sociedad, a partir de suponer la importancia del contexto social y cultural en el resultado de las mismas. Un poco antes de él, el sociólogo y filósofo George Hebert Mead había demostrado ya que la interacción comunicativa era una especie de respuesta de un organismo (en este caso el ser humano) al ambiente, de manera tal que la interacción se convertía en un modo de reaccionar ante el entorno. En los años 30's, por su parte, la Escuela de Chicago, centra en la interpretación la esencia del fenómeno comunicativo y demuestra empíricamente la influencia del contexto social y cultural en la interpretación de los seres humanos durante la comunicación. También, el Interaccionismo Simbólico otorgan a la comunicación un carácter social insoslayable ya que para estos teóricos, en la interacción social es donde se construyen los significados y las interpretaciones que se despliegan en las interacciones comunicativas, por lo que la interacción se conceptualiza como base o soporte de la comunicación. Posteriormente, junto a Goffman también, pero desde la Psicología, las aportaciones de la Escuela de Palo Alto y en específico las del antropólogo Gregory Bateson, ayudaron a comprender la importancia de la comunicación en las relaciones interpersonales, mismas que pueden constatarse a partir de los conceptos de homeostasis y doble vínculo, así como el valor comunicativo de todo comportamiento humano; metodológicamente, el modelo dramatúrgico de Goffman y el método etnográfico de Hymes y Gumperz, se instauraron como instrumentos eficaces para estudiar las interacciones comunicativas humanas.

${ }^{5} \mathrm{Su}$ escasa presencia y desarrollo en la docencia e investigación en comunicación obedece quizá al despliegue de la comunicación en todas las ciencias humanas y a su consecuente dilución como objeto de estudio. Como afirma Craig (citado en García, 2008), la comunicación es un proceso social que funda lo social, y no un fenómeno secundario que se explica a partir de factores sociológicos, culturales o psicológicos. En ese sentido, su imposibilidad para erigirse en disciplina obstaculiza la construcción de teorías y objetos de estudio propios, lo que la hace exponerse a los vaivenes del campo mismo y al desarrollo de otras disciplinas tradicionalmente afines.
} 
la sociología cultural y fenomenológica de donde emana el concepto de interacción humana y social como soporte del fenómeno y proceso comunicativo.

Por ello, este retorno a la sociología cultural y fenomenológica vincula al campo de la comunicación también con la psicología y en consecuencia, con la relación sujeto-sujeto en el marco más amplio de una relación sujeto-entorno. En ese sentido, la comunicación resulta pieza angular en tanto que ambas relaciones, dadas mediante la interacción interpersonal y/o sociocultural, se gestan y tienen lugar mediante el intercambio ${ }^{6}$ de información entre un sujeto y otro, o entre un sujeto y su entorno en su mutua relación de interdependencia en el ámbito de lo social.

\subsection{Comunicación intercultural, comunicación y comunicación humana}

Como ya hemos podido apreciar, la comunicación es proceso y es fenómeno. En tanto proceso, posibilita reflexionar sobre sus propiedades ontológicas y teleológicas; y en cuanto a fenómeno permite el estudio de una interacción específica dentro de esa totalidad. Es decir, como proceso la comunicación es un factor de socialización entre sujetos interactuantes que pone en marcha el intercambio de significados simbólicos con vistas a la producción y el reconocimiento de información relevante, sea institucionalizada o no, con respecto del proceso de adaptación de los sujetos al entorno; como fenómeno, la comunicación es evento, o sea, acontecimiento acotado por circunstancias espaciotemporales concretas donde se produce intercambio de significados con vistas a la producción y el reconocimiento de información relevante, sea institucionalizada o no, de un sujeto en relación con su entorno.

Esta distinción entre proceso y fenómeno valoriza la idea de la comunicación, en el primer caso como motor impulsor de las prácticas que hacen posible no sólo la construcción, organización y re-organización de lo simbólico en lo social, sino también la configuración histórica misma de lo social; y, en el segundo, caso la comunicación se da como situación interactiva concreta, es decir, como práctica social y cultural específica, discursiva o no, entre actores sociales cuyos comportamientos en el momento de la interacción poseen valor comunicativo para ambos hablantes, es decir, se configuran como prácticas de intercambio de información y significación, de manera que dicho intercambio revela incidencia en el desarrollo de la interacción.

\footnotetext{
${ }^{6}$ El concepto de intercambio en la comunicación fue acuñado por Ray Birdwhistell para quien la comunicación no podía concebirse en términos de acción-reacción, sino como un sistema en el que se intercambiaba información. para mayor información consultar: Birdwhistell, R. L. (1959) "Contribution of Linguistic-Kinesic Studies to the Understanding of Schizophrenia”. En Auerback, Alfred (ed.) Schizophrenia: An Integrated Approach. New York: Ronald Press, pp. 99-123.
} 
En consecuencia con lo anterior, en el entendido de que la comunicación intercultural es ante todo comunicación (Rizo y Romeu, 2006), cuando hablamos de comunicación intercultural nos referimos tanto al proceso como al fenómeno. De hecho, no puede pensarse siquiera lo intercultural fuera de los marcos conceptuales de lo comunicativo, pues lo intercultural indica, por terminología de origen "entre culturas", es decir, contacto interactivo entre culturas, del que nacen a su vez las relaciones simbólicas entre culturas que son las que configuran el orden histórico-social de lo multi o intercultural.

Además, lo intercultural nos obliga a reparar en su preferencia por el prefijo inter para hablar de una relación de equidad o simetría a pesar de las diferencias, y su discrepancia con los prefijos multi o pluri (vinculados a lo distinto y diverso, respectivamente) que son prefijos que no pocos asocian como semejantes cuando se habla de comunicación intercultural, a pesar de que muchos estudiosos del tema expresan serias diferencias entre los términos multiculturalidad, pluriculturalidad e interculturalidad ${ }^{7}$.

Por todo lo anterior, afirmamos que el sentido que anima a la comunicación intercultural, desde su etimología, implica comprenderla como una comunicación que expresa una relación de equidad o simetría, a pesar de las diferencias y desigualdades históricas que puedan existir entre las culturas en interacción. Pero, tal y como se plantea, esta relación es por principio y definición inexistente, por lo que la comunicación intercultural no puede ser evaluada en términos de la concreción de su hacer interactivo, sino más bien de su deber ser como relación; de ahí que la vaguedad con la que se inaugura el término "comunicación intercultural" resulta más un camino por hacer, que el análisis o la supervisión de un camino recorrido.

Al respecto Asunción-Lande plantea que la comunicación intercultural puede ayudar a crear una atmósfera que promueva la cooperación y el entendimiento de las diferentes culturas (Asunción-Lande, 1986: 179), lo que implica en los hechos que la tarea de la comunicación intercultural, además de la consabida explicación y explicitación del

\footnotetext{
${ }^{7}$ La multiculturalidad alude a la cohabitación de diferentes culturas dentro de un mismo espacio-tiempo; no busca sus puntos de contactos o rupturas, es un concepto que sólo da cuenta de la distinción cultural per se. Su origen es antropológico y como plantea Albretch (1999) puede resultar riesgoso en la justificación del estatus quo. En cambio, la pluriculturalidad se enfoca en la reivindicación de la diversidad simbólica, por lo que anula el sentido de comunión que expresa la interculturalidad. A pesar de esta distinción, algunos teóricos como Rodrigo Alsina o Francisco Colom, dan por hecho la equivalencia entre pluriculturalidad y multiculturalidad. Sin embargo, más allá de estas diferencias, en cualquiera de las dos variantes, la multiculturalidad y/o la pluriculturalidad describen la realidad social. La interculturalidad, en cambio, apunta hacia el deber ser de la relación entre culturas, es decir, hacia la interacción armónica entre culturas (Schmelkes, 2001); esa es la razón por la cual existe la comunicación intercultural, erigida como modo de transformación de esa realidad. Para mayor información consultar Albrecht, B. (1999). Antropología, desarrollo y cooperación (conferencia impartida en el congreso Antropología 2002, La Habana, Cuba, noviembre 2002) y Schmelkes, S. (2004), conferencia magistral dictada en la Universidad de Quintana Roo, agosto 2004.
} 
impacto de la cultura en la comunicación ${ }^{8}$, es la de intervenir en los procesos comunicativos que violentan esa atmósfera de cooperación y entendimiento a la que hace referencia la autora.

No obstante lo anterior, en la comunicación intercultural la posibilidad real de intervención a corto y mediano plazo se plantea al interior de un escenario de interacción a nivel interpersonal o grupal, a partir del cual si bien se pone en claro la relación entre la cultura y su impacto en la construcción de subjetividad de individuos y grupos, también se posiciona a la comunicación como un modo estratégico de intervención, es decir, como acción definida en términos clínicos y no como escenario de reflexión teórica o metodológica; a largo plazo, en cambio, el sentido de interacción armónica que subyace en este ideal no puede más que gestarse y construirse, a través del tiempo, mediante un largo proceso de socialización de carácter educativo que debe necesariamente comportar fuertes articulaciones con lo social, lo cultural, lo político, lo jurídico y lo ético.

La comunicación intercultural así entendida es un ejercicio práctico de la comunicación humana que tiende a la utopía, es decir, al trazado de trayectorias propias del accionar cultural a través de la transformación de la acción y el pensamiento humanos; de ahí que la función de intervención de la comunicación en los ámbitos empíricos de la comunicación intercultural quede expresada mediante lo que hemos intentado apuntar como camino teleológico de la comunicación.

\subsubsection{Orígenes y trayectorias de la investigación en la comunicación intercultural}

La comunicación intercultural surge como preocupación académica a partir de los años 60 's, pero no es hasta entrada la década de los 70 's que la producción de conocimiento teórico y empírico en ese campo se desarrolla con fuerza y se impone como parte de la investigación científica en las ciencias sociales. Dicha preocupación nace vinculada a la necesidad de hacer eficiente la comunicación entre sujetos de matrices culturales distintas, por lo que su aplicabilidad es intrínseca a su surgimiento y al sendero trazado, mayormente, por las investigaciones en el tema, sobre todo a partir de la expansión comercial y financiera de los Estados Unidos en Asia, amén de su intento de control político en América Latina, fundamentalmente, y la posterior expansión de China, Corea y Japón en Occidente. Esto hace suponer que la comunicación intercultural adquiere desde esos primeros años un matiz de "capacitación" o desarrollo de habilidades, vinculado estrechamente a la gestión empresarial, tanto pública como privada, al tiempo que va

\footnotetext{
${ }^{8}$ La tarea de explicación del impacto de la cultura en la comunicación no es nueva. Ha sido referida ampliamente por la sociología cultural, la microsociología, la psicología, la fenomenología, la semiótica, el análisis del discurso, los estudios culturales, los estudios de recepción, la filosofía de la cultura, etc.
} 
enfocándose de forma particular en el análisis de los factores que inciden en el surgimiento del conflicto comunicativo que se genera.

El objetivo práctico de la comunicación intercultural se va definiendo en torno a la reducción (o más bien, al intento de reducción) de las fallas en la comunicación entre sujetos mediante el desarrollo de habilidades comunicativas de tipo intercultural, mismas que pueden resumirse como sigue: el conocimiento de la cultura propia y el reconocimiento del impacto que dicha cultura ejerce en los actos comunicativos propios, la sensibilización frente a la cultura ajena evitando hacer generalizaciones y juicios estereotipantes, la adopción de una actitud abierta al cambio que permita contemplar como posibles escenarios de comunicación alternativos o distintos a los imaginados previamente y en ese sentido, el ajuste o flexibilización de los modos de vida y patrones de pensamiento de los hablantes en función del mantenimiento del acto comunicativo.

Como se puede observar, desde esta perspectiva, la tarea transformadora de la comunicación intercultural se enfoca en la forma de hacer eficaz interculturalmente un encuentro comunicativo. Sin embargo, si bien el desarrollo de habilidades y destrezas interculturales permite reducir el posible nivel tensional de conflictos entre hablantes con diferentes matrices culturales, esto sólo puede ser posible, como ya mencionamos, si se condiciona el desarrollo de dichas habilidades y destrezas a su inserción en un proceso de transformación de la concepción del mundo de los sujetos y los grupos en otros órdenes de la vida social y cultural, como el orden educativo, jurídico y político, por ejemplo.

$\mathrm{Y}$ es que la comunicación intercultural comporta variables de muy compleja operacionalización como son: el lenguaje, donde entran tanto los códigos verbales (idioma) como los no verbales; el patrón de pensamiento (Sarbaugh, 1979) que da cuenta de la forma en que analizamos la información proveniente de la realidad; y la concepción de la vida y del mundo de los sujetos, en tanto funcionan como concepciones cognitivas, de carácter interpretativo que tienen un papel fundamental en la configuración de las relaciones culturales mismas, pero también en la configuración de las relaciones sociales e interpersonales en general. Estas concepciones cognitivas, que son recogidas bajo el término de representaciones sociales (Moscovici, 2001), resulta quizá la variable más importante a tener en cuenta en la explicación de un conflicto comunicativo gestado en situaciones de interculturalidad, pues incide en el rol de las relaciones sociales propiamente dichas y en el rol concreto de los hablantes en una interacción comunicativa dada.

Debido a ello, los estudios en comunicación intercultural, hasta el momento, han buscado centrar su atención en la reducción de los riesgos del conflicto provocado por las diferencias culturales, lo que aunado a la pérdida del estado como un referente político nacional (Rodrigo Alsina, 1999), ha hecho que la comunicación intercultural focalice su atención hacia los temas urgentes de las sociedades actuales como la migración nacional e 
internacional, el multiculturalismo histórico de algunas naciones, la reivindicación de los grupos étnicos marginados y el replanteamiento de las identidades culturales, por sólo citar algunos.

En México, por ejemplo, el desarrollo de grupos de trabajo e investigación en comunicación intercultural hacen eco de estas temáticas, enfocándose básicamente en la relación cultura-identidad, con alguna aplicación en medios ${ }^{9}$. Sin embargo, este enfoque sigue observando la misma noción simbólica-antropológica en torno al concepto de cultura, sin problematizarla en su dimensión más micro. Por ello, no es de extrañar que actualmente en un país multicultural como lo es México las temáticas de reflexión en el campo de la comunicación intercultural hagan énfasis, mayoritariamente en la reivindicación cultural de los grupos étnicos históricamente marginados $y$, en consecuencia, en los procesos migratorios nacionales de diversos grupos indígenas, ya sea a la capital o a otros estados de la república. No obstante lo anterior, contrariamente a lo que pudiera pensarse, no hay investigación empírica sustentable en este tema ${ }^{10}$.

Una representación fuerte y formalizada en el campo de los llamados "estudios interculturales" en función de la temática indígena lo constituye el trabajo que sostiene el investigador Gunther Dietz en la Universidad Veracruzana en Xalapa, Veracruz, a través de la participación de su equipo de trabajo en el Cuerpo Académico de Estudios Interculturales. El proyecto bajo su cargo propone un trabajo de sistematización de los informes elaborados en torno a la problemática indígena, la diversidad étnica y la diversidad cultural por parte de organizaciones no académicas. La perspectiva de estudio de estos proyectos es transdisciplinar y se inserta en campos como la política, la antropología, la sociología, la lingüística, la pedagogía, la salud, etc.

Desde el punto de vista conceptual y metodológico, resulta interesante también el trabajo que, desde una perspectiva intersubjetiva, se realiza al interior de la línea de investigación en Comunicación Intercultural de la Universidad Autónoma de la Ciudad

\footnotetext{
${ }^{9}$ Información tomada de la página web de la Asociación Mexicana de Investigadores en Comunicación (AMIC). http//:www.amicmexico.org (fecha de consulta 5 de febrero de 2010)

${ }^{10}$ En una búsqueda realizada en la base de datos de Fuentes Navarro, se encontró que de más de 5000 registros sólo 23 documentos responden al descriptor "comunicación intercultural" y de ellos el grueso de los trabajos (15) se dividen en estudio o análisis de situaciones comunicativas entre extranjeros y mexicanos (8), y 7 en función de la reflexión teórica en torno al concepto de cultura. De estos últimos, 3 versan sobre la relación cultura, interculturalidad, representaciones sociales, 1 sobre la relación cultura, interculturalidad y lenguaje, otros 3 sobre la relación comunicación-cultura-interculturalidad, y el resto de los trabajos abarcan temáticas distintas como interculturalidad y política, interculturalidad y medios, interculturalidad y nuevas tecnologías, interculturalidad y educación, este último precisamente en el abordaje de la educación indígena. (la base de datos de Fuentes Navarro es el resultado de un trabajo de sistematización de la producción académica en el campo de la comunicación realizada por el Dr. Raúl Fuentes Navarro, del Instituto Tecnológico de Estudios Superiores de Occidente, Guadalajara, Jalisco. Para mayor información consultar: ccdoc.iteso.mx/acervo/ (fecha de consulta: 18 de febrero de 2010)
} 
de México, sobre la relación comunicación intercultural/fronteras simbólicas, en tanto que contribuye a dinamizar la reflexión en torno a los conceptos base de la comunicación intercultural.

\subsubsection{Escenarios y desafíos para los estudios en comunicación intercultural}

Dado todo lo anterior, consideramos que una visión más amplia sobre los temas de reflexión e investigación en comunicación intercultural debe conducir necesariamente a plantear dos grandes escenarios desde donde la comunicación intercultural puede pensarse teórica, conceptual y metodológicamente.

Primer escenario: enfocado en la diferencia cultural como factor obstaculizador de la comunicación. Aquí podemos observar dos perspectivas de trabajo:

1. Aquella que entiende a la cultura desde el punto de vista simbólico-antropológico, es decir, la cultura como conglomerado macro de sentidos culturales que demarcan simbólica y hasta geográficamente zonas de identidad claramente territorializadas. Este concepto de cultura aparece asociado al concepto de identidad cultural y al concepto de etnicidad. Los temas a tratar desde esta perspectiva son, por una parte, los conflictos culturales derivados de los procesos migratorios y los procesos de adaptación de los migrantes; y por la otra, los conflictos interculturales provocados por una persistente situación multicultural, como lo es el caso específico de las naciones multiculturales, temática que no sobra decir tiene su correlato en el ámbito de lo migratorio también. Aquí el concepto de diferencia adquiere un sentido de marginación cultural y social.

2. Aquella que se enfoca en la problematización misma de los conceptos de cultura y de identidad cultural, ya que ellos resultan estrechos cuando nos referimos al concepto de representación social de Moscovici (2001) o al de rasgos culturales de Grimson (2004: 57). Desde esta perspectiva se problematiza el concepto de cultura en términos de su relación con lo social, desde donde se delimita como campo o parcela de la producción de sentidos al interior de una misma red sociocultural (Bourdieu, 1990). Este enfoque en torno a la inserción de la cultura en lo social, permite hablar de lo sociocultural como lugar de despliegue de los diferentes universos de sentido o modos de significación e interlocución (Grimson, 2004: 41) propios de un grupo social y no necesariamente étnico. En ese sentido, la categoría de análisis que provee la homogeneidad simbólica en el grupo se halla demarcada por la representación que los sujetos hacen de su círculo de pertenencia (Giménez, 2000) o los llamados rasgos culturales de Grimson (2004) que son nociones que hacen oponer simbólicamente a 
un grupo con respecto a otro. Es por ello que ambas conceptualizaciones ponen el acento en los rasgos o elementos de distinción físicos o simbólicos de un grupo que, necesariamente, tiene que coexistir con otros en el espacio social, donde en consecuencia se gestan situaciones de tipo intercultural. Los temas a tratar mediante este enfoque son aquellos relacionados con el conflicto de género, el conflicto religioso, el conflicto de clases, el conflicto urbano-rural, el conflicto de preferencia sexual, el racismo, etc. (Pech, Rizo, Romeu, 2008). En esta perspectiva el concepto de diferencia se desterritorializa y adquiere un carácter simbólico que, por estar inscrito siempre en el ámbito de lo histórico-social, resulta muy vinculado a los procesos de construcción de creencias, imaginarios sociales e identidades intersubjetivas.

Segundo escenario: enfocado en la diferencia cultural como factor favorecedor de la comunicación. A diferencia del escenario anterior que está centrado en la relación de conflicto, este segundo escenario se posiciona en el no conflicto, a pesar de que parte necesariamente de éste. En este escenario, el concepto de diferencia adquiere carácter dialógico y las perspectivas de estudio e investigación son nuevamente dos:

1. El desarrollo de destrezas y habilidades comunicativas que permita a individuos y grupos el despliegue de competencias comunicativas interculturales. Desde esta perspectiva los ámbitos de trabajo son esencialmente metodológicos y se hallan vinculados al método de intervención para mejorar o transformar problemas vinculados a deficiencias comunicativas en situaciones de interculturalidad. Se parte de que dichos problemas son derivados de la falta de competencia comunicativa intercultural (Rizo y Romeu, 2008) y el propósito de este enfoque apunta de forma significativa a dar cumplimiento a la apremiante tarea de la comunicación intercultural de reducir el grosor de los conflictos interculturales. Aunque es un ámbito de trabajo que a través del registro de la implementación y desarrollo de proyectos de intervención social cuenta con una experiencia grande a nivel empírico, es el menos trabajado desde la comunicación a nivel teórico-conceptual.

2. La reflexión en torno a la relación dialógica entre la diferencia y la semejanza, o lo que viene a ser su conceptualización más filosófica entre lo uno y lo múltiple, entre lo diverso y lo mismo. Esta temática de estudio si bien ha sido hasta el momento más propia de la reflexión que de la investigación empírica, atraviesa sin duda todos los ámbitos y escenarios anteriores. Sus ámbitos de reflexión provienen del quehacer filosófico, sobre todo de la filosofía de la cultura y la hermenéutica, imbricados fuertemente ambos en una visión ética de la comunicación, cuya esencia se halla supeditada a la comprensión de la comunicación como interacción solidaria y empática. 
Como se puede notar, el segundo escenario plantea un desafío teórico y metodológico tanto en su primera variante como en la segunda. En la primera, si bien el desarrollo de habilidades y destrezas comunicativas resulta el objetivo primordial de la comunicación intercultural, desde esta esfera de la comunicación no se cuenta con el suficiente anclaje teórico en tanto carece de una vinculación sólida, por ejemplo, con la teoría de conflictos y los consecuentes enlaces metodológicos tales como la estrategia de negociación, dinámicas de rol, sociodrama, etc., ya que estas resultan herramientas que posibilitan el adiestramiento. A nivel de intervención, en cambio, el reto hasta el momento sigue siendo dar cuenta de su eficacia como método de transformación del entorno.

En la segunda variante, el desafío es diferente. Desde esta perspectiva facilitadora de los encuentros interculturales, abordar el tema de la diferencia, que es concepto base de toda comunicación intercultural, supone la conceptualización desde lo comunicativo de la relación dialógica entre diferencia y semejanza, lo que a su vez implica la necesidad de abonar la reflexión sobre la naturaleza misma de la interacción intercultural y la vinculación que comporta con lo dialógico como forma de expresión intercultural propiamente dicha. Hasta el momento, desde la comunicación, no se ha trabajado ni la una ni la otra. Justamente, en los apartados que siguen intentaremos subsanar esta carencia.

\section{Diálogo y comunicación intercultural}

\subsection{La comunicación intercultural y el otro}

A la investigación en comunicación intercultural le huelga mucha vinculación con el concepto postmoderno de otredad. La otredad o alteridad implica más allá del reconocimiento del Otro, el reconocimiento del sí mismo, es decir, la conciencia de la individualidad. Por eso, hay quienes afirman que la otredad es pérdida de la unidad del ser al tiempo que extrañeza ante lo distinto y ajeno.

El ser, ontológicamente hablando, es el todo inconsciente en el que habita la especie, su devenir natural donde no hay conciencia de sí y, en consecuencia, tampoco conciencia de la existencia de los otros. Desde esta perspectiva, el ser es uno más de lo mismo, no hay diferencia, no hay individualidad. Pero en esta ausencia de divisiones subyace, sin embargo, la diversidad. La no conciencia sobre la individualidad no implica ausencia de diversidad. El ser, lo perciba o no, está circunscrito a ser parte del todo, pero al mismo tiempo a tener que configurarse identitaria y subjetivamente ajeno a ese todo. La identidad individual aflora entonces desde la experiencia vital de un sujeto que se sabe desde ese 
momento separado del mundo indiviso al que creyó pertenecer por siempre; de ahí su extrañeza por lo diverso.

La conciencia del ser sobre la presencia de los otros y la relación distintiva entre ellos crea en el subconsciente la sensación de pérdida, o como dijera Heidegger, de arrojamiento, de desamparo (Heidegger, 1998). El ser en su individualidad potencia su soledad y es esa misma soledad, lejos de las diferencias físicas y culturales que distinguen a un individuo de otro, lo que hace al ser comprenderse como parte de un todo semejante, y comprenderse también, a la distancia, como parte escindida del mismo. Esa es la razón por la que afirmamos que el ser individual es incompleto, aunque no sea totalmente consciente de ello.

El individuo, después de esa escisión primordial, se acostumbra y acomoda a su sí mismo, de manera tal que todo lo que percibe fuera de su Yo queda confinado al ámbito de lo ajeno. Por la naturaleza limítrofe del Yo, el ámbito de lo ajeno es de extrañeza y de diferencia, percepciones ambas que se extienden más allá del individuo porque involucran a la colectividad. Como afirma Rodríguez, la otredad también tiende puentes con el concepto de cultura (Rodríguez, 2001: 114), por lo que la distinción, gestada de forma natural por la diferencia, plantea el problema del otro en escenarios de asimetría y desigualdad, tanto natural como cultural.

La dinámica entre el Yo y el Otro, que es también una dinámica esencial de la relación entre el Nosotros y el Ellos, revela una lógica de oposiciones entre culturas, pero también al interior de una misma cultura. Cada cultura, dice Lotman, crea sus propios opositores (Lotman, 1994: 126), y esto indica que la función de dicha creación, más allá de distinguir e individualizar, sea la de oponer, la de hacer visible la diferencia a pesar de las semejanzas. Así, la lógica de oposición del Nosotros vs Ellos devuelve al Ser a la lógica individualizada de la construcción de su identidad, es decir, al proceso de construcción de su sí mismo y a la afirmación de su sentido de pertenencia más allá del sentido primigenio de existencia.

El Otro es siempre lo que no es el Yo, y el Ellos en consecuencia es lo que está fuera del endogrupo, del Nosotros, o lo que es lo mismo, del grupo de pertenencia; el Ellos nunca es como los Míos. Al otro se le siente como extraño porque es diferente en un sentido distinto a la diferencia que separa a cada uno de los nuestros. Pero la diferencia del otro no es ontológica, no puede serlo. La diferencia del otro estriba en la diferencia percibida del Otro con respecto al Yo, y ello implica necesariamente una relación diferencial biunívoca entre la forma del otro y su contenido. ¿Quién es el Otro, se pregunta el Yo? ¿Qué es el Otro para mí y los míos? ¿Es el Otro prójimo o enemigo?

La insistencia de tales preguntas indica el nivel de inconsciencia o des-conocimiento que se tiene sobre la escisión primordial que da paso a la construcción de la individualidad pues cuando uno se plantea al Otro en esos términos parte de pensarlo como des- 
conocido ${ }^{11}$ y como lo que es ajeno al Yo por definición. Así entendido, el Otro no sólo se revela fundamentalmente distinto, sino también profundamente misterioso; sin embargo, hay misterio en principio, cuando hay desconocimiento real.

No obstante lo anterior, si bien es cierto que el misterio está asociado al desconocimiento, no debe soslayarse el hecho de que el misterio también va vinculado a lo que se le revela al Yo como des-conocido, es decir, a lo que por su propia naturaleza extraña y diferente cierra las puertas del entendimiento y la comprensión. No es que el Otro sea desconocido per se, es que el Yo lo advierte así porque su propia cosmovisión de vida le impide conocerlo.

Por ejemplo, en algunos grupos culturales (Grupo A) la relación distintiva entre el Yo y el Nosotros está menos diferenciado, por lo que el sentido de colectividad permea no sólo la organización económica, social y hasta política, sino también las relaciones familiares e íntimas de sus miembros. Por ello, el despliegue de prácticas como pedir permiso a la comunidad para contraer matrimonio, e incluso para deshacerlo, marcan una diferencia sustancial con aquellos grupos (Grupo B) que tienen bastante más diferenciado la relación entre el Yo y el Nosotros, y por ende no precisan del consentimiento comunitario para llevar a cabo un casamiento o un divorcio.

Para los miembros del grupo A resulta inconcebible casarse o divorciarse sin la aprobación colectiva, por lo que perciben en su mayoría a los miembros del grupo B no sólo diferentes, sino también descuidados e irrespetuosos, por ejemplo. En ese caso, el grupo B es juzgado a partir de la cosmovisión del grupo A y la razón de su juicio obedece no sólo al des-conocimiento, sino también a la manera en que el comportamiento del grupo B resulta inentendible, es decir, inexplicable para el grupo A, y viceversa. En ese sentido, el otro no es sólo un extraño, sino también alguien de quien no se sabe qué esperar.

No está de más señalar que el des-conocimiento y la falta de entendimiento entre los miembros de grupos culturales distintos expresa una relación mutua de temor, misma que en las relaciones interculturales provocan conflictos en ocasiones bastante irresolubles, como el conflicto religioso entre musulmanes y judíos en Jerusalén. Al no haber entendimiento se cancelan las vías para la comunicación en general y para la eficacia comunicativa en particular, generándose con ello un conflicto que puede ir más allá de los límites concretos de la interacción comunicativa en la que se da.

\footnotetext{
${ }^{11}$ Aquello que realmente se desconoce no se puede pensar. Lo desconocido es un término que se emplea para no revelar la responsabilidad que tenemos los seres humanos en la concepción del otro o de lo otro. Plantearse al otro como desconocido porque es diferente, implica otorgar forma y contenido a la diferencia y des-conocerlo arbitrariamente. En ese sentido utilizamos el vocablo "des-conocimiento" para hablar de lo que ignoramos conscientemente, y la palabra "desconocimiento" la reservamos para hablar de la ignorancia sana y ajena por ello a cualquier atributo de sentido.
} 
El temor y el des-conocimiento conducen tanto al rechazo del otro como a su represión, por lo que la tarea de la comunicación intercultural debe plantearse como un objetivo social que trasciende, en nuestra opinión, los reducidos marcos de la diferencia cultural. La tarea de la comunicación intercultural debe apuntar en términos teleológicos, al respeto y fomento de las diferencias desde posiciones donde se asuma un sentido de semejanza básico, primigenio. La conciencia de sí que individualiza al ser no puede enfocarse solamente hacia su distinción y aislamiento, pues eso implicaría abandonar el hecho de que también somos semejantes.

Esta concepción igualitaria de la naturaleza humana tan vieja como la vida misma, aunque muchas veces tan ajena a ella también, conduce a establecer puentes dialógicos entre los seres humanos que permiten responder preguntas como las que siguen: ¿cómo y qué se habla con el otro? ¿para qué sirve saber con/del otro? En un sistema mundo tan imperialista como el que hoy se vive (para usar una expresión bien conocida de Inmanuel Wallerstein), con derroteros éticos y sociales que apuntan cada vez más a la individualidad y la competencia, la comunicación intercultural tiene la imperiosa tarea de colaborar con esta "puesta en relación con" que el diálogo es capaz de reconducir. Nuestra propuesta, como se puede entrever, no está vinculada a la eficacia comunicativa, ni a lograr un grado aceptable de información compartida. Nuestra apuesta apunta a lo dialógico como modo de hacer converger lo semejante a pesar de y debido a, justamente, las diferencias. He ahí la importancia de reflexionar sobre el propósito de la comunicación intercultural y el sentido teleológico de la comunicación que de ella se deriva, a partir de la reflexión en torno al papel del diálogo en la configuración de las relaciones humanas.

\subsection{El diálogo como posibilidad estratégica de la comunicación con el otro}

La concepción hermenéutica sobre el diálogo apunta hacia la comprensión del sí mismo como instancia reflexiva potencial de apertura a lo diferente. Este criterio se inscribe en una larga tradición de la hermenéutica filosófica representada por Paul Ricoeur, Inmanuel Levinas y Gianni Vattimo; y, en particular, las posturas de Martin Buber, Mijaíl Bajtín y Hans Georg Gadamer, entre otros.

Para Ricoeur, el diálogo como hermenéutica se instala en los procesos de construcción de la subjetividad como condición autorreflexiva que necesariamente invade los predios del sentido, el lenguaje y en consecuencia de la comunicación, pero lamentablemente confina al lenguaje articulado la única potestad para hacerlo, lo que deja no sólo al diálogo anclado a lo racional, sino también al autoconocimiento y la acción transformadora del sí 
mismo varados a medio camino entre su despliegue liberador y los límites opresivos del lenguaje $\mathrm{e}^{12}$.

Por su parte Levinas, contrario a Ricoeur, cifra en la ausencia del lenguaje la verdadera posibilidad del despliegue dialógico, de ahí que la experiencia hermenéutica a partir del diálogo consista en una relación empática y solidaria vinculada al instante en que percibimos al otro como infinito (Levinas, 1999) y nuestra relación en comunión con él. Desde esta perspectiva, como se puede notar, al igual que pasa con Ricoeur, lo dialógico queda fuera del poder, es decir, queda fuera de las relaciones de poder desde cuyas configuraciones tiene lugar lo comunicativo.

Justamente, en estas coordenadas del poder en las relaciones dialógicas se instala el pensamiento de Vattimo para quien el diálogo se instituye entre el sujeto y la historia en un sentido interpretativo. Pero lejos de ser un diálogo integrador como lo propone Gadamer, defiende la idea de un diálogo interpelativo, es decir, de un diálogo que se efectúa desde la tradición histórica y, en múltiples ocasiones, en lucha contra ella. Por eso, para este pensador, el diálogo es motor de continuidad y huella, o sea, es la forma en que existimos como seres en el mundo.

Martin Buber, por su parte, considera al diálogo como un modo de relación directo y mutuo a través del cual se confirma el valor único de las personas, anclado en un tipo de relación que él denomina "de involucramiento" en la que el Yo participa del Tú, aunque no se funde con é ${ }^{13}$. A diferencia de las relaciones de desprendimiento que es otro tipo de relación que también, afirma Buber, construimos los seres humanos, en las relaciones de involucramiento no surge la necesidad de cosificar al Tú, y mucho menos de dominarlo o utilizarlo. Su definición del Yo como entidad que sólo puede existir en relación con el Otro, expresa una relación primordial de la experiencia del ser. De hecho, afirma el autor, cuando la experiencia del ser se da "en relación con", se despliega el mundo de la relación, que es el mundo de la experiencia participativa, es decir, de la experiencia presente, de la relación directa y mutua ${ }^{14}$. Esta relación, al igual que lo plantea Levinas, no puede estar mediada por el lenguaje que es por naturaleza limitado, sino solamente por lo dialógico, o sea, por ese "estar dos" en recíproca presencia que es donde se realiza y reconoce el encuentro de uno con el otro (Buber, 1990: 150-151).

\footnotetext{
${ }^{12}$ Como se puede observar hay una fuerte vinculación entre el pensamiento de Ricoeur y el de Gadamer.

${ }^{13}$ Esto marca una diferencia sustancial con el pensamiento de Levinas y su idea de la experiencia del infinito por parte del sujeto.

${ }^{14}$ Esta idea está muy vinculada también con el concepto de diálogo de Paul Freire sobre el sentido de horizontalidad en el diálogo (Freire, 1975, 1993) y la condición simpatética que determina la relación afectiva y amorosa presente en todo diálogo. Para el pedagogo brasileño el diálogo no puede anular la identidad, sino que reafirma sus distinciones. Esta idea postula el sentido del diálogo como comunidad (Freire, 1993), intersubjetividad y reflexividad.
} 
Como se puede ver, el diálogo para Buber, al igual que para Bajtín, es relación, inclusión. De hecho, para el lingüista ruso la vida humana tiene una naturaleza dialógica y la expresión adquiere sentido en la proyección de esa vida hacia el exterior, es decir, hacia el otro (Bajtín, 1996, p. 32). Por ello, ya en Los géneros del discurso y otros ensayos, de 1986, Mijail Bajtín señalaba que no hay voces que no retomen ni remitan a otras ya que ningún orador es ni puede ser más que un "respondente" de otras voces (Bajtín, 1986). De esa manera, dice el autor, el ser no puede ser menos que comunicación dialógica, es decir, comunicación en la que no se puede dejar de tener en cuenta la voz del otro.

Este "tener en cuenta a" confina justamente el quehacer dialógico a un escenario donde no se permite la apropiación individualizada en tanto importan ambos "hablantes", no sólo uno. Por ello para Bajtín sólo mediante el diálogo puede darse una continua construcción de significados, es decir, sólo mediante el diálogo se impide la construcción de significados fijos, su permanencia en el tiempo y su legitimación como verdad. En ese sentido, el diálogo se instala como lugar de la apertura, de lo inconcluso, de lo indefinido, porque la multiplicidad de voces y sentidos desde la que se construye, gesta de forma intrínseca su movimiento y su transformación.

Como se puede notar, a pesar de estas posturas disímiles, el concepto de diálogo articulado desde la hermenéutica permite apreciar cómo la relación del sujeto con su sí mismo sucede a través de la relación con el otro; por ello, creemos, resulta importante reflexionar sobre el papel del diálogo como proceso interactivo donde ocurre necesariamente el intercambio de información significante que posibilita el impulso de los procesos de construcción de la subjetividad y de aquellos vinculados a la transformación de los sujetos individuales y sociales al interior de los mismos.

Precisamente es en ese sentido que consideramos al diálogo como posibilidad de la comunicación con el otro, misma que, acotemos nuevamente, no responde a criterios de eficacia, es decir, no está vinculada a escenarios comunicativos donde se pretende esclarecer la intención, la naturaleza o el impacto de un efecto, sino más bien donde se intenta dar luz a los flujos de intencionalidad propios de toda expresión (Peiffer, 2002: 260-261), o lo que es lo mismo, a la posibilidad dialógica como contacto apertural hacia lo desconocido que es ajena a su vez a la intención de cualquier discurso o juicio.

A todas luces, la concepción del diálogo como posibilidad estratégica de la comunicación con el otro se soporta en el acto de la expresión per se, es decir, en la interacción misma, y ello ubica al contacto con el otro -que es hasta ese momento desconocido y por ello ajeno y diferente- en el umbral mismo de toda posibilidad dialógica. En ese sentido, y basados en todo lo anterior, es que proponemos al diálogo como posibilidad estratégica de la comunicación con el otro, nunca como destino -como dijera Buber- sino como espacio para el encuentro mismo. 


\subsection{Diálogo, diferencia y comprensión}

La relación entre diálogo y comprensión proviene de la tradición hermenéutica europea, de la mano de Hans Georg Gadamer. En esta era de la interpretación, el destronamiento del sentido fundamentador propio de la metafísica moderna instala la preocupación sobre el hombre como ser en el mundo, es decir, sobre la condición histórica y existencial del sujeto. A esto, justamente, se reduce el legado gadameriano cuando se refiere a la comprensión del ser como su condición ontológica.

Influido por el pensamiento de Heidegger, Gadamer habla de la comprensión en términos de sentidos sobre el mundo, en una especie de co-implicación entre mundo, sujeto y lenguaje. La comprensión es para él una suerte de proyección de la existencia del ser en el mundo, mediante la cual también el mundo cobra existencia; de ahí lo que se conoce como círculo hermenéutico. Sin embargo, a pesar de este, al parecer, círculo cerrado, determinado y determinante que el propio Heidegger dejó entrever, para Gadamer, la categoría del diálogo resultará parte de la comprensión e interpretación del ser en el mundo, ofreciendo con ello una perspectiva de la hermenéutica que supera la consciencia del sujeto. Para este filósofo, lo dialógico se articula a partir de la existencia de lo "aún no dicho", es decir, a partir de una fuente de sentido inexplorada. Con ello, Gadamer aporta al diálogo la posibilidad de ser una experiencia de comprensión provisional sobre el sí mismo pues, para el autor, el ser existe, al igual que para Heidegger, comprendiéndose, sabiéndose, en tanto plantea que la comprensión del ser es, ella misma, su determinación (Heidegger, 1998: 35).

Como se puede apreciar, es mediante su conceptualización de diálogo que Gadamer apela a un concepto de comprensión creativo pues en sus propias palabras "cuando se comprende, se comprende siempre de modo diferente" (Gadamer, 2004: 366-367). Esto hace que siempre podamos acceder al sí mismo desde lugares distintos, aún y cuando la condición histórica de nuestra existencia limite efectivamente dicho acceso. En ese sentido, si bien la experiencia de comprensión como diálogo se presenta desde la condición histórica y transitoria del ser, por esa misma razón el ser accede a un universo de sentido cuya verdad es transitoria también, es decir, parcializada, provisional. Por ello, la comprensión de sí y del otro es un modo de existencia del ser que está enmarcado al mismo tiempo por el sentido apertural del diálogo y por su carácter limitado ante la historia.

No obstante lo anterior, la comprensión dada mediante el diálogo posibilita la transformación del ser, ya que la comprensión de la existencia afecta directamente su existencia, es decir, la modifica, dotándola de nuevas posibilidades; así, este fenómeno dialógico se inscribe al interior de un fenómeno de comprensión del mundo en el que 
también habitan otros seres y otras culturas. Es por ello que el diálogo siempre se construye desde la diferencia, o como dijera Gadamer, desde lo no explorado. En ese sentido, no puede referirse a lo dialógico como lo que tiende al entendimiento, sino más bien lo que tiende a la comprensión ${ }^{15}$.

La idea de comprensión explica la posibilidad de "ponerse en relación con", aunque no se entienda y mucho menos se comparta una visión del mundo. La comprensión apunta a la existencia misma del diálogo porque apunta de manera esencial hacia el reconocimiento y respeto de la diferencia. Puede haber comprensión a través de la empatía ${ }^{16}$, aunque no haya formalmente entendimiento. La comprensión del otro es siempre comprensión del sí mismo. El otro es, como hemos mencionado, el complemento del ser, el rostro perdido que, una vez encontrado, aunque distinto y distante, es también, de alguna manera, uno mismo. Al comprender la naturaleza del otro, el yo limitado y carente, partido y escindido, recobra su unidad.

Para que el diálogo tenga lugar, es necesario, entonces, identificar las diferencias y explicarlas a la luz de la comprensión como modo de complementación del sí mismo, es decir, explicarlas a la luz de comprender que las diferencias del otro no son ajenas al Yo porque completan su ser, o al menos, en términos de una pragmática más realista, completan la idea de que la realidad no tiene una sola cara, es decir, no tiene una sola perspectiva; la realidad, es diversa y esa diversidad es la que constituye el todo de donde provenimos y donde nos movemos.

El diálogo así entendido, expresa una condición interactiva de la comunicación que precisa de intercambio de información entre sujetos. Dicho intercambio genera afectaciones en todas las partes involucradas, pero eso sólo puede hacerse si el punto de partida de la interacción prevé la existencia de la diferencia como oportunidad para ampliar la mirada hacia el todo, o lo que es lo mismo como oportunidad para escuchar la voz del otro, sin suponer de antemano su decir. Este modo de relación comunicativa conduce a la posibilidad de escuchar la voz del otro, a través del Yo. Como afirma Pablo Quintanilla, "las condiciones de la interpretación [que no son otras, como afirma

\footnotetext{
${ }^{15}$ La relación entre diálogo y diferencia es inmanente. No puede haber diálogo desde posiciones iguales porque habría únicamente entendimiento o acuerdo; un diálogo desde el entendimiento estaría tendiendo a lo coincidente, y en lo coincidente no hay pluralidad, es decir, no está representado lo diverso. En una palabra, en el diálogo no basta entender, hay que comprender.

${ }^{16}$ Estamos refiriéndonos al concepto de empatía desde una perspectiva no intencionalista, es decir, ajena a la teoría transportacional de la empatía por medio de la cual se explica la forma en que un individuo reproduce los escenarios mentales del otro. Esta concepción defendida ampliamente por Locke y Dilthey se aleja de lo que en este trabajo pretendemos erigir como empatía que es la capacidad de imaginar ser el otro, misma que está más vinculada a la llamada Teoría de la simulación, más cercana a la concepción de representación mental y esfuerzo creativo de la mente que en este trabajo se ha venido abordando.
} 
Gadamer, que la condiciones de la comprensión $]^{17}$ nos exigen ver al otro como un semejante-diferente. Por lo diferente que es, nos cuestiona y se convierte en un reto permanente para nuestras propias creencias y deseos, así como nos obliga moralmente a intentar entenderlo, porque nuestra auto-comprensión está estrechamente ligada a la comprensión del otro" (Quintanilla, 2004: 94).

\section{La comunicación dialógica como estrategia para la construcción y despliegue de competencias comunicativas interculturales}

\subsection{Diálogo y comunicación dialógica}

La comunicación dialógica es la comunicación sostenida por medio del diálogo y el diálogo, como ya hemos apuntado, se expresa como condición de existencia del otro en la que está contenida la comprensión. En ese sentido, lo que conduce a comprender al otro no es sólo el camino para su reconocimiento, su tolerancia o su aceptación, sino el sentimiento amoroso ${ }^{18}$ que posibilita la escucha profunda, es decir, la escucha del otro a través de la escucha del sí mismo.

Sin embargo, es evidente que el sujeto no ama a todo el mundo, ni ama siquiera de la misma manera ni con la misma intensidad; de hecho, el sujeto no ama siempre. Por ello, la concepción holista de una ética de la comprensión como la que se propone en este trabajo, debe, necesariamente, afirmarse a través de una ética de la interpretación a lo Vattimo, que anularía a su vez toda posibilidad de erigir un sentido moral de la comprensión mediante la comunicación.

La comprensión del sí mismo a partir de la comprensión del otro, desde la perspectiva comunicacional que hemos intentado construir aquí, defiende, justamente, la idea de su imposibilidad; no porque en la práctica el ser no pueda prescindir de ello (lo que hace evidentemente mediante el despliegue de su voluntad y deseo), sino porque el intercambio de información que supone toda relación de reconocimiento del otro en un

\footnotetext{
${ }^{17}$ Los corchetes son de la autora.

${ }^{18}$ Entendemos el sentido del amor en términos de solidaridad o caridad, no como virtud moral, sino como philia, es decir, como cuidado del otro y de uno mismo. Esta idea ha sido desarrollada específicamente por Pablo Quintanilla en "El lugar de la racionalidad en la comprensión del otro", en S. López, G. Portocarrero, R. Silva y V. Vich (eds.), Estudios Culturales. Discursos, poderes y pulsiones. Lima: Red para el desarrollo de las Ciencias Sociales en el Perú. 2001; aunque también la han trabajado desde otras aristas Humberto Maturana en Desde la biología a la psicología. Santiago de Chile: Edición Universitaria, 1995, y Paulo Freire en Pedagogía de la esperanza. México: Siglo XXI, 1993. También la ha trabajado Martin Buber en su libro Yo-tú (1969), de cuyas generales se da cuenta al interior de este trabajo.
} 
espacio de sentido medianamente compartido, resulta la condición misma de toda acción humana y social en el mundo.

Es justamente por esta dimensión volitiva de la comprensión que consideramos al deseo, o sea, a las ganas de querer comprender al otro, un problema no menor en torno al fenómeno de la comprensión. No hay que olvidar que la disposición sensorial y racional hacia el Otro puede obstaculizar el natural proceso de interpretarlo, porque, como hemos abordado anteriormente, a través de la construcción de un terreno compartido no sólo se tiende a construir una comunidad de creencias, significados y valores, sino también, y debido justamente a ello, a cuestionar nuestras más arraigadas convicciones en el plano epistémico y moral.

Esa es la razón por la que, insistimos, la comprensión es un proceso mayormente utópico hacia donde deben tender los comportamientos físicos y mentales de los individuos y sujetos. Su naturaleza efímera y dinámica indica que se trata de un modo de ser del sí mismo a través del otro que es altamente selectivo y que requiere una buena dosis de esfuerzo, autorreflexión y autocrítica. Por ello, la construcción de competencias interculturales al interior de la comunicación dialógica no puede ser entendida como "receta" o "pasos" para alcanzar la armonía en las relaciones entre culturas, o entre sujetos con matrices simbólicas distintas, sino como problemas graves a resolver que hasta el momento plantean un reto insoslayable para la reflexión teórica y la investigación empírica en torno a la problemática intercultural.

\subsection{Comunicación dialógica y competencia intercultural}

Según algunos teóricos de la comunicación intercultural, la forma adecuada y flexible ante acciones o significados puestos en marcha por sujetos de grupos culturales distintos, resulta el modo en que debe entenderse la competencia intercultural (Meyer, 1994). Chen y Starosa (1996), por su parte, definen la competencia intercultural como la habilidad para negociar los significados culturales y actuar eficazmente en términos comunicativos. Y para Miquel Rodrigo, la competencia intercultural se alcanza cuando se llega a un grado de comprensión aceptable para los interlocutores (Rodrigo, 1999).

Como se puede observar, las dos primeras definiciones apuntan hacia la eficacia comunicativa, y todas hacia la conservación funcional del proceso de la comunicación, aunque es justo decir que definición de Rodrigo Alsina se centra en el grado de comprensión y aceptación de los interlocutores (que es a fin de cuentas una noción muy extensa tanto de lo que puede ser comprensión, como de lo que puede ser aceptable), por lo que consideramos que deja mayor posibilidad para pensar la competencia intercultural como habilidad que debe gestarse bajo las circunstancias concretas que nosotros hemos 
propuesto como diálogo, mismas que dependen, en gran medida, de la disposición de los sujetos a la hora de interactuar.

En el apartado anterior definimos al diálogo como el modo de expresión y relación entre dos hablantes diferentes; sin embargo, nos parece importante señalar que el diálogo intercultural parte de concebir dichas diferencias como manifestaciones cognitivas y comportamentales que tienen su origen en la cultura, es decir, en el escenario donde tienen lugar las desiguales luchas y negociaciones por los significados y por su legitimación (González, 1987). En ese sentido, el diálogo intercultural se comporta como una variedad específica de diálogo, mismo que siempre está signado por lo comunicativo.

Por ello, si bien la comunicación está presente en todo despliegue dialógico, el empleo de competencias comunicativas interculturales propias de las interacciones comunicativas o contactos comunicativos interculturales mediante el diálogo, requiere de que éste sea comprendido como diálogo intercultural. Dicho diálogo puede ser aún más difícil de gestarse dado que las propias culturas gestan los modos en que se relacionan al interior y al exterior de ella (Grimson, 2004: 41-45) ${ }^{19}$. Si entendemos la cultura como una malla de significados que organiza la experiencia individual y colectiva y le da sentido a la vida (González, 1987; Bourdieu, 1990; Brislin, 1981; Bodlye, 1994; Geertz, 1987), la información cultural no resulta más que un condicionamiento, una red estructurante a lo Bourdieu que, en principio, debido a que la socialización de individuos y grupos se lleva a cabo justamente en ella, no resulta fácil ni cómodo desestimar.

En ese sentido, como ya hemos referido con anterioridad, en la comunicación intercultural hay dos posiciones básicas: una que tiende al conflicto y otra que tiende al no conflicto. La primera se define como aquella situación comunicativa en la que la diferencia cultural de los hablantes impide u obstaculiza la posibilidad de comprensión mutua. La segunda, refiere a la situación comunicativa en la que a pesar de la diferencia comunicativa, los hablantes tienden a la comprensión mutua.

Como abordamos en apartados anteriores, referirnos a la concreción real sobre la comprensión del otro no es algo posible en todos los casos. La comprensión del otro, y en consecuencia, del sí mismo se da de forma efímera y cambiante; su despliegue podemos definirlo como un destello instantáneo que en la medida en que logre abarcar o extenderse lo más posible al otro, se abona en pos de su consecusión. Esta instantaneidad de la comprensión revela la fragilidad misma del proceso dialógico, y hace voltear la mirada a la imposibilidad de ignorar el papel del poder en la configuración y desarrollo de las interacciones comunicativas, aún en situaciones de comunicación dialógica.

La comunicación dialógica es un proceso que requiere deseo y voluntad para dejar de lado, en alguna medida, las relaciones de poder que nos configuran como Yo y la

${ }^{19}$ Grimson se refiere a los "campos de interlocución" que son marcos interpretativos donde ciertos modos de identificación e interpretación son posibles y otros quedan excluidos (Grimson, 2004). 
conciencia de sí que desplegamos tanto en lo individual como en lo social al interior de una situación comunicativa dada; la comunicación dialógica tiende a reducir el nivel o grosor de los conflictos interculturales a través de la disposición de los sujetos para hacer "visible" la voz del otro, es decir, para ofrecer al otro la oportunidad de interactuar tal cual es. No se trata, como muchos han sugerido, de aceptar ni asumir los significados del otro, sino más bien de comprender que la diferencia del otro engendra la diversidad del todo; de ahí la necesidad de adquirir consciencia sobre nuestras propias cosmovisiones y comprender que la diferencia del otro no puede ser ontológica, sino simple y llanamente cultural.

\section{Referencias bibliográficas}

Asunción-Lande, N. (1986). "Comunicación Intercultural”. En Fernández Collado, C. (ed.) La comunicación humana. México: Mc Graw Hill.

Bajtín, M. (1982). Estética de la creación verbal. México: Siglo XXI (trad. Tatiana Bubnova).

Bajtín, M. (1986). "Speech Genres and Other Late Essays". En Caryl Emerson y Michael Holquist (eds.). Trad. Vern W. McGee. Austin: University of Texas Press.

Bateson, G. y Ruesch,J. (1984). Comunicación. La matriz social de la psiquiatría. Barcelona: Paidós.

Berger, P. y Luckman, Th. (1998). La construcción social de la realidad. Buenos Aires: Amorrourtu.

Bodlye, J.H. (1994). "An Anthropological Perspectives". En Cultural Anthropology: Tribes, Status and the Global System. Artículo en línea en: http//: www.wsu.edu.8001/vcwsu/commons/topics/culture/culture-definitions/bodley-text.html (fecha de consulta mayo 2008).

Bourdieu, P. (1990). Sociología y cultura. México: Fondo de Cultura Económica.

Brislin, R. W. (1981). Cross-Cultural Encounters: Face-to-Face Interaction. New York: Pergamon Press.

Buber, M. (1969). Yo y tú . Trad. Horacio Crespo. Buenos Aires: Nueva Visión.

Buber, M. (1990). ¿Qué es el hombre? México: Fondo de Cultura Económica.

Chen, G.M. y Starosa, W.J. (1996). "Intercultural Communication Competence: A Synthesis". En Burelson B.R. y Kunkel A.W. (eds.) Communication Yearbook, Núm. 19. Londres: Sage Publications, pp. 353-383.

Instituto de Historia y Filosofía (comp.) (1987). Tesis sobre Feuerbach. La Habana, Cuba: Editorial Gente Nueva.

Gadamer, H.G. (2004). Verdad y método I. Salamanca: Sígueme.

García Canclini, N. (1996). "Comunicación intercultural: hacia un balance teórico en América Latina". En Tecnología y comunicación educativa, Año 10, núm. 26, enero-junio. México: Instituto latinoamericano para la comunicación educativa, pp. 60-64

Geertz, C. (1987). La interpretación de la cultura. México: Gedisa. 
Giménez, G. (2000). “Materiales para una teoría de las identidades sociales”, en Valenzuela Arce, José Manuel (coord.) Decadencia y auge de las identidades. Cultura nacional, identidad cultural y modernización. México: Colef-Plaza y Valdés, pp. 45-78.

González, J. (1987). "Los frentes culturales: culturas, mapas, poderes y luchas por las definiciones legítimas de los sentidos de la vida”. En Estudios de las Culturas Contemporáneas, Época 1, Núm. 3. México, Colima: Universidad de Colima, pp. 5-44.

Grimson, A. (2004). Interculturalidad y comunicación. Bogotá: Norma.

Heidegger, M. (1998). El ser y el tiempo. Santiago de Chile: Editorial universitaria.

Levinas, I. (1999). El tiempo y el otro. Barcelona: Paidós.

Lotman, I. (1994). "Para la construcción de una teoría de la interacción de las culturas (el aspecto semiótico)”, en Revista Criterios No. 32, Cuarta Época, julio-diciembre, pp. 117-130.

Lotman, I. (1999). Cultura y explosión. Lo previsible e imprevisible en los procesos de cambio social. Barcelona: Gedisa.

Maturana, H. y Varela, F. (1986). El árbol del conocimiento. Santiago de Chile: Edición Universitaria.

Meyer, M. (1994). "Developing Transcultural Competence: Cases of Advanced Language Learners". En Genesse, F. (comp.) Educating Second Language Children: the Whole Child, the Whole Curriculum, the Whole Community. New York: Cambridge University Press, pp. 159-182.

Morin, E. (1995). "La noción de sujeto". En: Dora Fried (comp.) Nuevos paradigmas, cultura y subjetividad. Buenos Aires: Paidós.

Moscovici, S. (2001). Social representations: explorations in social psychology. New York: New York University Press.

Pech, C; Rizo, M; Romeu, V. (2008). Manual de comunicación intercultural. Una introducción a sus conceptos, teorías y aplicaciones. México: Biblioteca del Estudiante de la Universidad Autónoma de la Ciudad de México.

Pfieffer, M. (2002). “Intención e intencionalidad. Aportes para aclarar un equívoco”. En ÉNDOXA: Series Filosóficas, n." 16, pp. 255-270. UNED, Madrid. Artículo también disponible en línea en: http://e-spacio.uned.es/fez/eserv.php?pid=bibliuned:Endoxa-200295BB78BB-2199-BEB05722-B3A10903FC12\&dsID=intencion_intencionalidad.pdf (fecha de consulta 20 diciembre 2009).

Piaget, J. (1973). Estudios de psicología genética. Buenos Aires: EMECE.

Quintanilla, Pablo (2004). "Comprender al otro es crear un espacio compartido: caridad, empatía y triangulación". En Ideas y Valores, revista colombiana de Filosofía, agosto, núm. 125. Bogotá, Colombia: Universidad Nacional de Colombia, pp. 81-97. Artículo también disponible en línea en: www.ideasyvalores.unal.edu.co/resumenes/n125resumenquintanilla.htm (fecha de consulta 25 enero 2010).

Ricoeur, P. (2001). Del texto a la acción. Ensayo de hermenéutica II. Buenos Aires: Fondo de Cultura Económica.

Rizo, M. y Romeu, V. (2006). "Hacia una propuesta teórica para el análisis de las fronteras simbólicas en situaciones de comunicación intercultural". En Estudios sobre las Culturas 
Contemporáneas. Época II, Vol. XII, Núm. 24, Diciembre. Programa Cultura. Universidad de Colima, pp. 35-54.

Rizo, M. y Romeu, V. (2008). "Investigación-acción-participativa y comunicación intercultural. Relato de una experiencia de investigación con estudiantes de dos universidades de la ciudad de México". En revista Razón y Palabra número 65. Artículo también disponible en línea en: www.cem.itesm.mx/dacs/publicaciones/logos/N/n65/varia/vromeu_mrizo.html (fecha de consulta 10 de febrero de 2010).

Rodrigo Alsina, M. (1999). La comunicación intercultural. Barcelona: Anthropos.

Rodríguez Villafuerte, B. (2001). "El encuentro con el otro: historia de expansión y conquista”. En: La palabra y el hombre, No. 120. México: Universidad Veracruzana, Xalapa.

Romeu, V. (2007). "Hacia una pragmática del deseo: los medios y la construcción del "saber hacer” intercultural". En Revista In Texto No. 15, enero-junio, artículo disponible en línea en: www.intexto.com

Sarbaugh, L. (1979). Intercultural Communication. Rochelle Parks New Jersey: Hayden.

Vattimo, G. (1990). La sociedad transparente. Barcelona: Paidós.

Vattimo, G. (1992). Más allá del sujeto. Nietzsche, Heidegger y la hermenéutica. Barcelona: Paidós.

Waztlawick, P. (1993). Teoría de la Comunicación humana. Barcelona: Herder. 